\title{
EPISTEMOLOGICAL AND DIDACTIC ASPECTS OF ELEARNING. THE ROLE OF ELECTRONIC MODELS IN TEACHING/LEARNING Nicoleta SÄMÄRESCU*
}

\section{Abstract}

The eLearming instruments that have been researched in the last few years represent a necessity for the Romanian primary school also within the development of the alternative learning sources. These cognitive instruments as D. H. Jonassen names them, are utilized in the USA and are researched in other countries, too (France) in order to be implemented. The aim of this article is to implement and to recommend the utilization of electronic models: text and image processing sheets, presentation sheets, spreadsheets in the teachinglearning process in primary school.

According to this aim, the research hypothesis has been issued in keeping with which we anticipate to be able to offer a well thought training in the eLearning field by updating the teaching and learning process with the help of the implementation of a set of electronic models which will increase the intercepting coefficient, the motivation, stimulation, imagination and enthusiasm degree for the learning actors and will redefine the teacher-pupil relation. The main objectives which derive from the hypothesis of our study confine to establishing the impact of electronic models of the eLearning Set that has been proposed to be implemented on the actors primary school in the teaching-learning process; rendering the teaching-leaming process efficient by implementing cognitive models with electronic support; working out an operational guide that contains scientific-practical recommendations and lesson models that utilize PeL; enriching the mathematical thinking.

The study sample covers a population that wishes to know, to participate in the implementing of the new technologies. The sample was composed as follows: 121 teachers in primary schools, most of them students of the University in Pitești, 158 pupils and 47 parents whose children are primary school pupils.

Keywords: teaching-leaming process, electronic models, cognitive models

* Nicoleta SAMARESCU is a university assistant teacher, $\mathrm{PhD}$ Candidate at the Doctoral School of Sciences of Education, University of Bucharest. E-mail: nicoleta.samarescu@gmail.com 


\section{Introduction}

This paper argues in favour of the support of a new orientation in the innovative didactic methodology (that manifest nowadays in several countries in America, Asia, Europe) connected to the set of learning theories applied to this domain as well as the informational processing theory, constructivism, connectivism, biopedagogism etc. we also mention that the valences and the values added by the electronic instruments that have been proposed in the implementation of the educational process in the schools in Romania as well as in the Balkan Area, are indispensable in the nearest future. Hence, the need for updated, enriched information and for an increased motivational percentage we should also bear in mind that the time dedicated by the young generation as compared to the amount of knowledge is even smaller nowadays, that is why we should use these new "extra-options" positively in order to ensure the success of the new generation that "studies differently" and that should be consequently trained.

The reasons why we support the efficient didactic introduction and practice of these eLearning instruments, especially with operational-cognitive values could be the following: the low cost, their usability in various domains, the facility of working out effective custom lessons, the provability of the transferring effects of their utilization, the easier, more rapid and thorough way to understand certain mathematical concepts.

In the future, the electronic instruments will be standardized and will be utilized not only episodically in the scholar training processes, but even with adults. Although nowadays these eLearning models seem to be only anticipatory, once they are implemented they will become familiar and they will make the boundaries between the rural and the urban teaching permeable, they will create real premises for the increase of the successful personal projects in life.

\section{International context of electronic models}

Electronic models learning (especially by using spreadsheets) has also been implemented in primary school. In their article entitled Spreadsheets, pedagogic strategies and the evolution of meaning for variable, Kirsty Wilson, Janet Ainley from the Institute of Education at University of Warwick and Liz Bills from the School of Education and Lifelong Learning, University of East Anglia, as representatives of the English School, consider that the spreadsheets help especially in understanding abstract concepts in mathematics (Wilson, 2005: 322). Spreadsheets are powerful instruments to be used in teaching maths in primary school, gymnasium and high school. They offer "real models to explore the abstract concepts in maths and other subjects (...). A spreadsheet is 
a helpful instrument for the visual learners (...). The spreadsheet instruments lead the way towards problem solving, asserts Pamela Lewis who is a Computer Coordinator at St. Luke School in Brookfield (Lewis' 2006). In Intégration d'outils informatiques dans l'enseignement des mathématiques: étude du cas des tableurs Mariam Haspekian, a representative of the French School, points out numerous advantages of the spreadsheets as a tool when passing from arithmetic to algebra, among which "the interest in creating problems, especially through the trying/ error method, fosters the comprehension of formula and variable precepts, going from the particular to the general, it helps the reflection, the organization and the control of the work." In The Utilization of Software Instruments in Teaching Maths (Utilisation des outils logiciels dans l'enseignement des mathématiques), Jean Pierre Bouvier, also from France, together with de Philippe Sérès, Yves Olivier (specialists in algorithms and spreadsheets) and Bernard Aguer present the advantages of the spreadsheets utilized in high school teaching (Bouvier et alii, 2008: 79-82). Within an annual conference in San Antonio Oscar Chavez, from the University in Missouri, made out a case for his option to utilize the spreadsheet: its dynamic nature, the possibility to see the result of the operation immediately, the possibility to do several operations simultaneously, they can be a natural remedy for the introduction of the variable precept, they can be applied to any operation system (Chavez, 2003).

The spreadsheet is to Sergei Abramovich "an instrument for the complete development of the mathematical concept problem solving", presenting interesting ways to utilize the spreadsheet - with higher levels of education (gymnasium, high school) - in two-variable polynomial solving and as the Fibonacci numbers generator (Abramovich and Leonov, 2009: 3-40). The article On Mathematical Problem Posing by Elementary Pre-teachers: The Case of Spreadsheet by Sergei Abramovich si Eun Kyeong Cho presents the importance of the electronic instruments as tools in mathematical problem posing. The authors claim that the power of this electronic instrument is so great that "at the elementary level, by using a spreadsheet, one can turn a routine arithmetical problem into a challenging mathematical investigation." Numbers used to pose a problem as the previous data may become parameters (variables) that one can use to pose a new similar exercise. In other words, the availability of technology-enabled variation of the syntactic structure provides a source of new problems. The article also presents the advantages of solving Diophantine equation in two or three variables (which they study at the secondary level) (Abramovich and Cho, 2008: 1-19).

The Australian Steve Sugden from the Bond University notices in his article Spreadsheets: An Overlooked Technology For Mathematics Education the necessity to include spreadsheets in the teaching-learning process: "Electronic spreadsheets have been with us for more than 25 years, yet in Australia, they are not common in mathematics classes." Although this 
electronic model - the spreadsheet - is present on essentially every desktop or computer, it is often routinely ignored for mathematical modelling and instruction. His reference aims at using the MS Excel which presents numerous advantages, among which its ubiquity, and it was also used within other lessons: "When superior tools such as Excel are widely available, it is difficult to understand the graphics calculators choice."Thus, the Mathematics and Computation professor says that he questioned mathematics educators and offered them some suggestions for its incorporation into the mathematics classroom, motivating that more than half of the students (almost $60 \%$ ) do not know certain mathematical concepts easier to understand with the spreadsheets as a leaming tool (Sugden, 2007: 68-74). The same author presents the possibility to create different games with MS Excel, for instance Sudoku puzzle based on the set theory in the article The spreadsheet as a tool for teaching set theory: Part I - an Excel lesson plan to help solve Sudokus (Sugden, 2005: 68-70).

A perspective of the spreadsheet as a tool in the educational context in Turkey is offered by M. Miraç Özar in the article Spreadsheet in education, where he mentions a few motivational aspects: "The teacher is not only responsible for teaching his or her subject but also for making the subject enjoyable and motivating." The cognitive and the psychomotor aspects are also very important to mention. The final conclusion was that more supporting materials about different ways of teaching lessons with Excel should be available. "Spreadsheets build an ideal bridge between arithmetic and algebra (...). Therefore, spreadsheets have become an important part of many different curricula at different levels of education." (Özgün-Koca, 2000: 3-4). The researcher Keith Jones from the Southampton University has an important point of view to spreadsheet as a tool. Out of the short presentation entitled Using Spreadsheets in the Teaching and Learning of Mathematics: A Research Bibliography, we find out that "although not designed as an educational tool, (spreadsheets) have been used in mathematics classrooms since they first became available" in the teaching-leaming process in England. The researchers' opinions regarding the spreadsheet electronic model converge towards the same idea supported also by the Great Britain representative, K. Jones: "One way that seems to help pupils move from a non-algebraic to an algebraic approach is through work with spreadsheets." (Jones, 2005: 30). A paper which combines the theoretical with the applied side based on spreadsheet work is IT in Primary Science written by Roger Frost. We find in it several reasons to convince us use this electronic model: "spreadsheets have an astonishing range of functions that can help with maths", "spreadsheets can work out the total or average of a column, look for maximum or minimum values and turn any mathematical trick." The IT tools for processing information in the educational process include database programs and flow charts, spreadsheets programs, water, temperature, pressure, position sensors (less known to us, they are presented in the pictures as peripheral elements of computers). An example of using light 
sensors within the natural science lesson starts from the question Which colour should a cyclist wear? and the pupils are to identify the light level with the help of the sensor connected to the computer (Frost, 2004: 27-35). Another complex work about the organization and application of spreadsheets in the educational process is Spreadsheet Magic by Pamela Lewis which includes no less than 40 lessons at the elementary school level for the following domains: social studies, science, music, mathematics. From the kindergarten level up to the sixth grade one, the lessons include a theoretical part as well as computer activities (Lewis, 2006). The representatives of the Italian School, M. G. Bartolini Bussi, G. Chiappini, D. Paola, M. Reggiani and O. Robutti, present the newest research regarding the IT\&C technology used in school in their article entitled Learning Mathematics with Tools. At national level, the proper electronic tools such as spreadsheets, Power-Point presentations teaching-leaming database programs are little studied and rarely applied as didactic instruments.

\section{The experiment in the Romanian primary school}

The principal research aim is represented by the building-enrichingupdating of the teaching-learning process with the help of some new electronic models easy to be utilized by the learning actors. The models have been held as efficient and effective by numerous specialists (above mentioned). The experiment was taken on 158 pupils distributed as follows: 58 in the 2 nd form (rural and urban), 56 pupils in the $3 \mathrm{rd}$ form, 44 pupils in the 4 th form. The experimental and control classes were correspondingly chosen as to be equivalent (grades in Maths, the training level, the social background).

The U-Mann-Whitney test was applied which tests the difference between independent groups. Thus, the statistic hypotheses have been confirmed or disproved, according to the $p$ parameter. After the calculation of the $p$ parameter values, $\mathrm{p}=.884, \mathrm{p}=.833$ and $\mathrm{p}=.836$ respectively were obtained in the pre-test and $p=.022$ (2nd form), $p=.026$ ( $3^{\text {rd }}$ form), $p=0.14$ ( $4^{\text {th }}$ form) in the post-tests. After examining the values, the following conclusions have been drawn:

- there have been close results in the pre-testing of the same level classes, therefore the classes can constitute the basis of the experiment;

- by obtaining significant differences in the pre-tests we can infer that the electronic models which make up the eLearning Set meant to be utilized in the teaching-learning process have a positive influence on the pupils included in the experiment.

At this point we will present the values and the diagram corresponding to the standard deviation for the pre-test and the post-test in the case of teaching-learning with the help of eLeaming models. One can notice that the influence (perceived by the U-Mann-Whitney test) of the electronic models 
utilized in the test is an important one (the marks were equated to grades as follows: "FB" ("Very Well") to 10, "-FB" to 9.50, "B" ("Well") to 9, "-B" to 8.50 , "S" ("Satisfactory") to 8 or 7).

Picture 1 illustrates the situation of the youngest pupils that have been pre-tested ( $2^{\text {nd }}$ form) whose average grade is 9.46 .

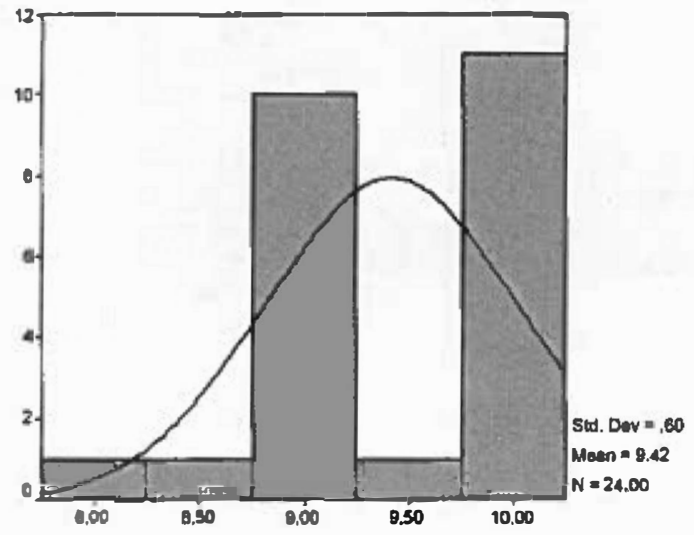

nota pro-lest the pre-testing grade

Figure 1. Pre-testing Diagram - 2nd form

In the case of the post-test the same pupils have obtained the 9.77 average grade (see Picture 2), which indicates o positive influence of the eLearning models (better results).

Clasa a II-a Metoda 2

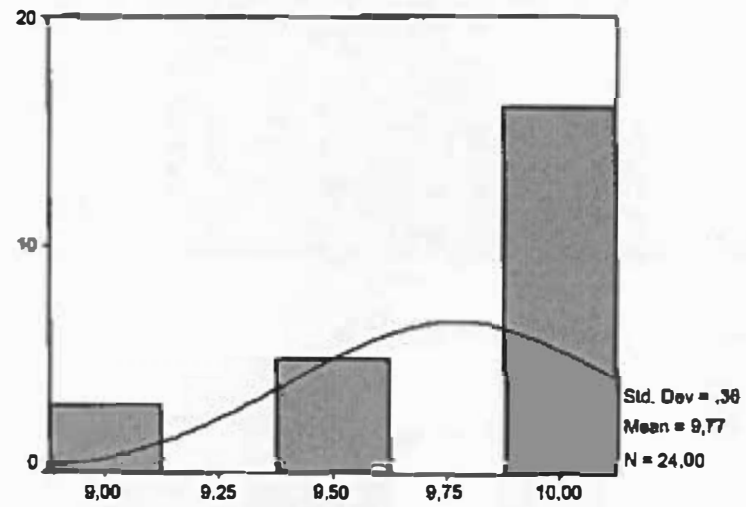

nota post-lest the post-testing grade

Figure 2. Post-testing Diagram $-2^{\text {nd }}$ form 
Clasa a III-a Metoda 2

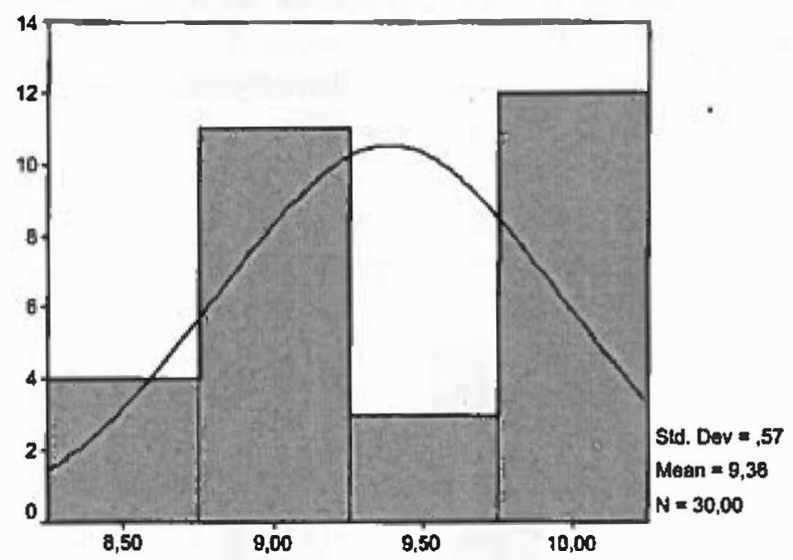

nota pro-test the pre-testing grade

Figure 3. Pre-lesting Diagram $-3^{\text {rd }}$ form

The $3^{\text {rd }}$ form got the 9.38 average grade (see Picture 3 ) in the electronic models pre-test, while in the post-test there was an increased average grade: 9.63 (see Picture 4).

Clasa a III-a Metoda 2

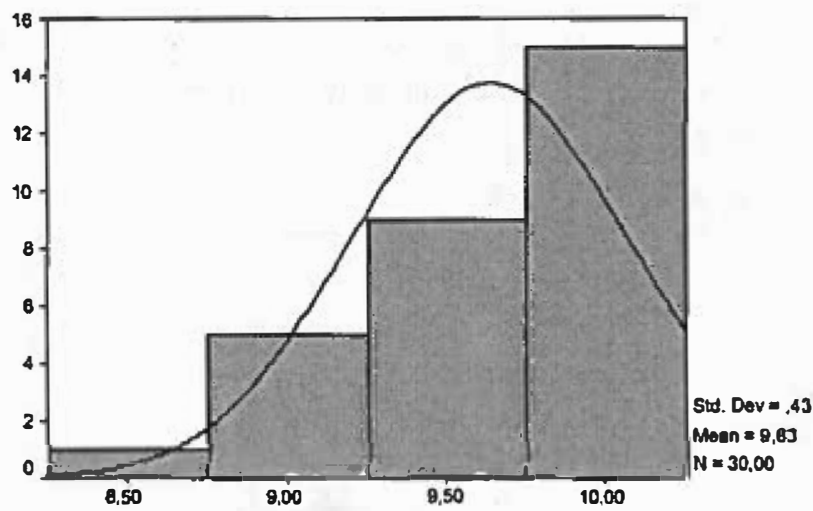

nota post-lest the post-testing grade

Figure 4. Post-lesting Diagram $-3^{\text {rd }}$ form

For the oldest of the tested pupils, the $4^{\text {th }}$ graders (final form in the primary school system), the difference between the pre-test and the post-test is significantly increased as compared to the other primary forms. They got 8.7 in 
the pre-test (see Picture 5), and 9.27 in the post-test (see Picture 6). There are a few explanations for the increased value

Clasa a IV-a Metoda 2

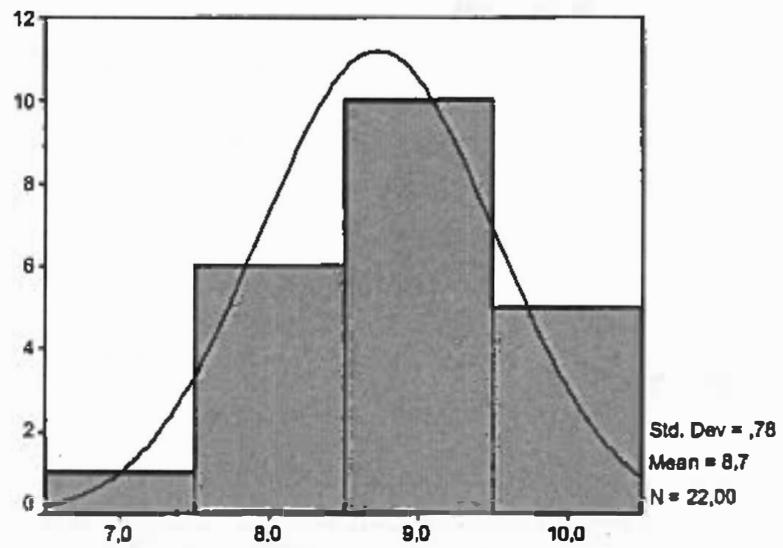

nota pre-test the pre-testing grade

Figure 5. Pre-testing Diagram $-4^{\text {th }}$ form

of the grades in the post-test in the case of the $4^{\text {th }}$ graders as compared to the youngest pupils: greater experience in the computer work; their higher level of receptivity to new types of lessons; the reward which practically does not exist in the traditional class attracts them more; the multitude of the pictures and games is much desired in the learning process (in opposition with the Maths books which contain gradually - from the $1^{\text {st }}$ form to the $4^{\text {th }}$ form - fewer pictures); the Maths abstract notions are more and more rarely explained through pictures (in the auxiliary books this thing does not exist).

Clasa a IV-a Metoda 2

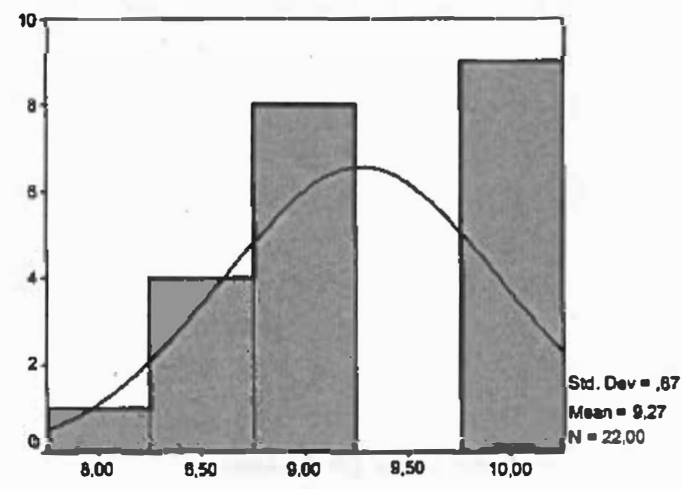

nota post-lest the pre-testing grade

Figure 6. Post-testing Diagram $-4^{\text {th }}$ form 
According to all the tested statistic hypotheses and standard deviation value we can infer the following:

- the pupils' performances increase when there are utilized teachinglearning electronic models;

- influences are more obvious in the case of older pupils (see the pretesting and post-testing values for the $4^{\text {th }}$ form);

- the electronic models utilized for the $3^{\text {rd }}$ and $4^{\text {th }}$ forms were the ones that are Microsoft PowerPoint-based;

- the electronic models utilized for the $2^{\text {nd }}$ form had the Microsoft Excel-spreadsheet as their starting point.

\section{The eLearning Set}

The eLearning models (spreadsheet, presentation sheet, text sheet) in the Set suggested by us should fulfil several conditions in order to develop the pupils' abilities necessary to carry on activities within the European Union:

- "A well-thought soft should limit the number of wrong answers for each problem - a modality certain to create frustration is to ask a student to repeatedly guess the answer to a problem he/she does not know to solve! Another danger in this case is to encourage casual answers in damage to reasoning' (CNIV, 2007: 383)"

- the interactive lessons are built using a cognitive map (idea map, mind map, concept map or cognitive models); a cognitive map is an operational concept often used in order to visualize and develop ideas, to represent information, to understand and memorize concepts;

- the electronic models are meant to develop creativity (to allow the pupils to make up new problems to solve), to stimulate curiosity for scientific study (the newly-acquired concepts should be searched on the internet, utilized and developed in different projects);

- the e-lessons should develop a critical, systematic thinking;

- the e-lessons should lay the foundations for the digital abilities necessary to the standard Europass tests required later on in the Romanian teaching system;

- the electronic learning syllabus should gradually increase their difficulty levels, to be easily accessed and to offer a feed-back;

- the e-lessons should ask the pupils think of the transdisciplinary concepts, encourage them in the perspective of collaboration leaming, even monitor their progress;

- the electronic instruments can detect phenomena that are not to be perceived by human eye and they can render them much faster than by speech. 


\section{The efficiency and the effectiveness of the guide}

The guide addressed to schoolmasters, Methodist schoolmasters, primary school teachers, inspectors, teachers within the continual formation programs, senior teachers in faculties who assist numerous degree inspections, young researchers interested in the eLeaming implemented in primary school and even parents helps them respond faster and better to the present and future necessities of the human subject and community, respond the challenges of the new millennium during which the learning actors develop.

The necessity of this guide is fully justified because the electronic learning system has well defined roles and actors just as in the classical social environment.

The total/partial application of the eLearning Set in the educational process both in the European Union countries and in the countries on the other continents leads to the need of an aware implementation, as a well coordinated phenomenon of the new technologies in the educational process.

An approaching strategy of the instructive-educational process is the focus in the pupil. A redefining of the teacher's roles is required. Thus, the eLearning Set helps the teacher gain the partner position in the educational activity, adopt an operational, applicable position or the teaching interdisciplinary structuring, facilitate experiential truths.

The more and more increasing amount of work for the teachers in the primary school system - by applying the numerous teaching strategies, combining the scholar and extra-scholar activities, intelligent organization of lessons, necessity to acquire a certain score for the personal evaluation etc. requires a minimum training in the technological domain for a maximum and lasting effect.

No matter what the older or newer teaching theories might be about, even if they are centred on the teaching methods at a pedagogical and psychological level, they have a matter that is sustained by eLeaming.

The eLearning is the result of both the new evolutions related to the leaming theories and of the applicability/utilizability of the communication and evaluation technologies.

Without denying the truth of the saying Success requires support at both ends, we state the case for the fact that ensuring the quality of the educational process depends to a great extent on the teachers' training and abnegation. 


\section{Bibliography}

1. ABRAMOVICH, S., CHO, E. K. (2008). Spreadsheets in Education On Mathematical Problem Posing by Elementary Pre-teachers: The Case of Spreadsheets. In Revista eJSiE, Volume 3, Issue 1. (http://epublications. bond.edu.au/cgi/viewcontent.cgi? article $=1050 \&$ context=ejsie, accesat 10.10.2009).

2. ABRAMOVIC, S., LEONOV G. A. (2009). Spreadsheet and the discovery of new knowledge. Spreadsheet in Education, Vol. 3, Iss. 2, pp.1-42., Berkeley Electronic Press. (http://epublications.bond.edu.au/cgi/viewcontent.cgi?ar ticle $=1060 \&$ context $=$ ejsie, accesat 10.01.2010).

3. BOUVIER, J. P., SÉRĖS, P., OLIVIER, Y., AGUER, B. (2008). Algorithmique au lycée: apports du tableur. In Actes du séminaire national "Utilisation des outils logiciels dans l'enseignement des mathématiques". (http://media.

education.gouv.fr/file/Formation_continue_enseignants/18/6/actes_math_et_tice 110186.pdf, accesat 27.02.2010).

4. CHAVEZ, O. (2003). Spreadsheets and algebra. NTCM Annual Meeting, San Antonio. (pe http://web.missouri.edu/chavezo/nctm03/nctm03.pdf, accesat 10.06.07).

5. JONES, K. (2005). Using Spreadsheets in the Teaching and Learning of Mathematics: a research bibliography. In MicroMath, 21(1), 30-31. (http://eprints.

soton.ac.uk/41324/01/Jones_MMResBiblio_Spreadsheets_2005.pdf, accesat 03.03.2008).

6. LEWIS, P. (2006). Spreadsheet Magic (second edition).Washington: ISTE Publications.

(http://books.google.ro/books?id=gJ7FE0VWPpsC\&printsec=frontcover\&dq=P amela + Lewis ++ Spreadsheet + Magic $\& c d=1 \# v=$ onepage $\& q=\& f=$ false, accesată 07.09.2009).

7. NEACSU, I. (1990). Instruire şi învăłare. București: Stiinł̣ifică.

8. NEACSU, I., SÄMĀRESCU N. (2009). Elearning and New Approaches in Primary Education. $4^{\text {th }}$ International Conference on Manufacturing Science and Education (MSE) - Trends in Engineering and Academic Education, 4-6 iunie, Sibiu, 2009.

9. ÖZGÜN-KOCA, M.A. (2000) Using spreadsheet in mathematics educations. ERICCISME No. 3/2000 pp. 3-4 ERIC Digest (http://www.gpo access.gov/eric/200210/ed463951.pdf, accesat 12.09.2009).

10. POTOLEA, D., NEACSU, I., IUCU, R., PÂNISOARĀ, I.-O. (2008). Pregătirea psihopedagogică. Manual pentru definitivat şi gradul didactic II. Iași: Polirom.

11. SUGDEN, S. J. (2005). Spreadsheets in Education. The spreadsheet as a tool for teaching set theory: Part I - an Excel lesson plan to help solve 
Sudokus. Revista eJSiE, Volume 2, Issue 3 (http://www.ausims.org.au/Gazette/ 2007/May07/ 068ClassroomNotes.pdf, accesat 09.09. 2009);

12. SUGDEN, S. J. (2007). Spreadsheets: an overlooked technology for mathematics education In Gazette Vol. 34, Nr. 2 (pp.68-74) (http://www.austms.org.

au/Publ/Gazette/2007/May07/Gazette34(2)WebVersion.pdfHpage=8, accesat 03.09.2009).

13. WILSON, K, ANLEY, J., BILLS, L. (2005). Spreadsheets, pedagogic strategies and the evolution of meaning for variable. (revista Psychology of Mathematics Education, Vol. 4, pp. 321-328. (www.pme.uk, accesat 04.06.07). 